\title{
PENGARUH PENGETAHUAN PENDERITA TB PARU TERHADAP TINGKAT KEPATUHAN BEROBAT DI PUSKESMAS ARUT UTARA PANGKUT
}

\author{
${ }^{1}$ Rukmini Syahleman, S.Kep., Ners., M.Kep \\ ${ }^{1}$ STIKes Borneo Cendekia Medika Pangkalan Bun \\ 1Email : rukminisyahleman@ gmail.com
}

\begin{abstract}
ABSTRAK
Tuberkulosis (TB) adalah salah satu masalah kesehatan yang harus dihadapi masyarakat dunia. Setiap tahunnya, TB menyebabkan hampir dua juta kematian, dan diperkirakan saat ini sekitar sepertiga penduduk dunia telah terinfeksi kuman TB. Tingkat kesembuhan yang belum 100\% disebabkan oleh kurang kedisiplinan bagi penderita TB Paru sangat dipengaruhi oleh beberapa factor yang salah satunya adalah faktor pengetahuan. Pengetahuan seseorang yang kurang tentang suatu penyakit khusunya TB paru akan mempengaruhi tingkat kepatuhan berobat. Tujuan penelitian ini adalah menganalisis pengaruh pengetahuan penderita TB paru terhadap tingkat kepatuhan berobat di Puskesmas Arut Utara Pangkut. Penelitian ini merupakan penelitian Queasy Experiment (pre dan post test design). Populasi dalam penelitian ini adalah seluruh pasien TB paru di Puskesmas Arut Utara Pangkut dengan teknik sampling yang digunakan adalah total sampling. Hasil penelitian didapatkan ada pengaruh pengetahuan penderita TB paru terhadap tingkat kepatuhan berobat di Puskemas Arut Utara Pangkut $(p=0.014)$. Saran yang diberikan peneliti adalah diharapka Puskemas Arut Utara Pangkut tetap melaksanakan pendidikan kesehatan secara kontinue tidak hanya di area khususnya upaya preventif promotif kuratif dan rehabilitasi penyakit TB paru.
\end{abstract}

Kata kunci : Pengetahuan, Tingkat Kepatuhan Berobat, TB Paru

\section{EFFECT OF KNOWLEDGE OF LUNG TB PATIENTS ON THE LEVEL OF COMPLIANCE WITH TREATMENT IN NORTH PUTKUT ARUT HEALTH CENTER}

\begin{abstract}
Tuberculosis $(T B)$ is one of the health problems that must be faced by the world community. Every year, TB causes nearly two million deaths, and it is estimated that currently around a third of the world's population has been infected with TB germs. The cure rate that has not been 100\% caused by lack of discipline for patients with pulmonary $T B$ is strongly influenced by several factors, one of which is the knowledge factor. A person's lack of knowledge about a particular disease of pulmonary $T B$ will affect the level of compliance with treatment. The purpose of this study was to analyze the effect of the knowledge of pulmonary TB patients on the level of compliance with treatment at the Arut Utara Pumpang Health Center. This research is a Queasy Experiment study (pre and post test design). The population in this study were all pulmonary TB patients at Arut Utara Pumpang Health Center
\end{abstract}


with the sampling technique used was total sampling. The results showed there was an influence of the knowledge of pulmonary TB patients on the level of compliance with treatment at the North Arut Public Transport Center $(p=0.014)$. Suggestions given by researchers are expected to North Arut Public Transport Center of North Sumatra continue to carry out continuous health education not only in the area, especially in efforts to preventive promotive curative and rehabilitation of pulmonary $T B$ disease.

Keywords: Knowledge, Treatment Compliance Level, Lung TB

\section{PENDAHULUAN}

Tuberkulosis (TB) adalah salah satu masalah kesehatan yang harus dihadapi masyarakat dunia. Indonesia sekarang berada pada ranking kelima negara dengan beban TB tertinggi di dunia. Estimasi prevalensi TB semua kasus adalah sebesar 660,000 (WHO, 2010) dan estimasi insidensi berjumlah 430,000 kasus baru per tahun. Jumlah kematian akibat TB diperkirakan 61,000 kematian per tahunnya ${ }^{(1)}$. Dirjen Pengendalian Penyakit dan Penyehatan Lingkungan Kementerian Kesehatan Republik Indonesia tahun 2011 melaporkan bahwa Indonesia telah diakui keberhasilannya dalam pengendalian $\mathrm{TB}$, hal ini dibuktikan dalam laporan Global Report Update tahun 2009 bahwa Indonesia berhasil menurunkan posisinya dari posisi 3 menjadi posisi ke 5 sebagai negara dengan jumlah pasien TB terbanyak di dunia.

Kesembuhan atau keberhasilan pengobatan ini ditentukan oleh beberapa faktor, terutama kepatuhan dalam minum obat, untuk mempertahankan kepatuhan diperlukan dukungan dan motivasi dari orang- orang disekitar. Besarnya angka ketidakpatuhan berobat akan mengakibatkan tingginya angka kegagalan pengobatan penderita TB paru dan menyebabkan makin banyak ditemukan penderita TB paru dengan BTA yang resisten dengan pengobatan standar. Hal ini akan mempersulit pemberantasan penyakit TB paru di Indonesia.

Pengetahuan seseorang yang kurang tentang suatu penyakit khusunya TB paru akan mempengaruhi tingkat kepatuhan berobat. Dimana penderita TB paru yang mempunyai pengtahuan yang rendah atau pengetahuan yang kurang terhadap penyakit TB paru maka kencenderungan penderita tidak patuh pada upaya pencegahan penyembuhan penyakit TB paru dengan benar maka kecendrungrungan tingkat prosentase angka ketidaksembuhan penyakit TB paru meningkat sehingga penderita TB paru juga tidak sembuh.

\section{METODOLOGI PENELITIAN}

Desain penelitian yang digunakan dalam penelitian ini adalah Queasy Experiment dengan rancangan pre dan 
post test design. Jumlah sample pada penelitian ini adalah sebanyak 50 responden. Seluruh subjek responden ini di observasi dahulu kepatuhan berobat sebagai pre-test. Kemudian diberikan intervensi berupa pengetahuan penderita TB paru tentang Penyakit TB paru. Setelah 7 hari kemudian, dilakukan observasi ulang, sebagai post-test. Uji statistik yang digunakan adalah uji statistik wilcoxon.

\section{HASIL PENELITIAN}

\section{A. Data Umum}

a. Usia

Tabel 1 Distribusi Frekuensi Usia

Responden penderita TB paru di Puskesmas Arut Utara Pangkut

\begin{tabular}{ccc}
\hline Umur & Jumlah & Prosentase \\
\hline $\begin{array}{c}<\mathbf{2 0} \\
\text { TAHUN }\end{array}$ & 6 & 12.0 \\
$\mathbf{2 0}-\mathbf{4 0}$ & 19 & 38.0 \\
$\begin{array}{c}\text { TAHUN } \\
>\mathbf{4 0} \\
\text { TAHUN } \\
\text { Total }\end{array}$ & 25 & 50.0 \\
\hline
\end{tabular}

Berdasarkan tabel 1 separuh dari responden di Puskesmas Arut Utara Pangkut berumur lebh dari 40 tahun sebanyak 25 responden (50\%).

b. Jenis Kelamin

$\begin{array}{rlr}\text { Tabel } 2 & \text { Distribusi } & \text { Frekuensi } \\ & \text { Jenis } & \text { Kelamin } \\ & \text { Responden penderita } \\ & \text { TB paru di Puskesmas } \\ & \text { Arut Utara Pangkut }\end{array}$

\begin{tabular}{ccc}
\hline $\begin{array}{c}\text { Jenis } \\
\text { kelamin }\end{array}$ & $\begin{array}{c}\text { Frekue } \\
\text { nsi }\end{array}$ & $\begin{array}{c}\text { Pers } \\
\text { en }\end{array}$ \\
\hline $\begin{array}{c}\text { LAKI- } \\
\text { LAKI }\end{array}$ & 14 & 28.0 \\
$\begin{array}{c}\text { PEREMP } \\
\text { UAN }\end{array}$ & 36 & 72.0 \\
Total & 50 & 100.0 \\
\hline
\end{tabular}

Berdasarkan 2 sebagian besar jenis kelamin responden penderita tb paru di Puskesmas Arut Utara Pangkut berjenis kelamin perempuan sebanyak 36 responden $(72 \%)$.

\section{B. Data Khusus}

a. Tingkat kepatuhan berobat penderita TB paru sebelum diberi pengetahuan di Puskesmas Arut Utara Pangkut .

$\begin{array}{rrr}\text { Tabel } 3 & \begin{array}{l}\text { Distribusi } \\ \text { tingkat }\end{array} & \text { Frekuensi } \\ & \text { kepatuhan } \\ & \text { sebelum } & \text { diberi } \\ \text { pengetahuan } & \text { di } \\ & \text { Puskesmas } & \text { Arut Utara } \\ & \text { Pangkut }\end{array}$

\begin{tabular}{ccc}
\hline $\begin{array}{c}\text { Tingkat } \\
\text { Kepatuhan }\end{array}$ & Jumlah & Prosentase \\
\hline $\begin{array}{l}\text { Tidak } \\
\text { Patuh }\end{array}$ & 12 & 24.0 \\
Patuh & 38 & 76.0 \\
Total & 50 & 100.0 \\
\hline
\end{tabular}

Berdasarkan tabel 3 Tingkat kepatuhan sebelum diberi pengetahuan di Puskesmas Arut Utara Pangkut adalah patuh sebanyak 38 responden (76\%).

b. Tingkat kepatuhan berobat penderita TB paru setelah diberi pengetahuan di Puskesmas Arut Utara Pangkut

Tabel Distribusi Frekuensi

4 tingkat kepatuhan

setelah diberi

pengetahuan di

Puskesmas Arut

Utara Pangkut 


\begin{tabular}{lcc}
\hline $\begin{array}{c}\text { Tingkat } \\
\text { Kepatuhan }\end{array}$ & Jumlah & Prosentase \\
\hline Tidak & 6 & 12.0 \\
Patuh & & \\
Patuh & 44 & 88.0 \\
$\quad$ Total & 50 & 100.0 \\
\hline
\end{tabular}

Berdasarkan tabel 4 Tingkat kepatuhan setelah diberi pengetahuan di Puskesmas Arut Utara Pangkut adalah patuh sebanyak 44 responden $(88 \%)$.

c. Pengaruh pengetahuan penderita TB paru terhadap tingkat kepatuhan berobat di Puskesmas Arut Utara Pangkut .

$\begin{array}{llr}\text { Tabel } & \text { Pengaruh } & \text { pengetahuan } \\ 5 & \text { penderita } & \text { TB paru } \\ & \text { terhadap } & \text { tingkat } \\ & \text { kepatuhan berobat di } \\ & \text { Puskesmas Arut Utara } \\ & \text { Pangkut }\end{array}$

Test Statistics ${ }^{a}$

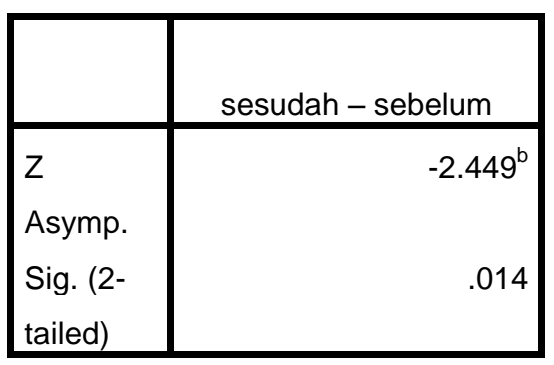

a. Wilcoxon Signed Ranks Test

b. Based on negative ranks.

Berdasarkan tabel 4.5 diatas diperoleh hasil Asymp. Sig (2 tailed) sebesar 0,14 . Karena nilai Sig 0,014 $<0,05$ maka dapat disimpulkan bahwa ada Pengaruh pengetahuan penderita TB paru terhadap tingkat kepatuhan berobat di Puskesmas Arut Utara Pangku.

\section{PEMBAHASAN}

Tingkat kepatuhan sebelum diberi pengetahuan di Puskesmas Arut Utara Pangkut adalah patuh sebanyak 38 responden (76\%). Kepatuhan seorang penderita terhadap program pengobatan tidak begitu saja bisa terjadi. Dibutuhkan sebuah proses yang diawali dari pengetahuan, sikap dan akhirnya diwujudkan dalam sebuah prilaku atau tindakan. Kepatuhan (adherence) adalah suatu bentuk perilaku yang timbul akibat adanya interaksi antara petugas kesehatan dan pasien sehingga pasien mengerti rencana dengan segala konsekuensinya dan menyetujui rencana tersebut serta melaksanakannya. Kepatuhan terhadap sepuluh hari jadwal pengobatan sejumlah $70-80 \%$ dengan tujuan pengobatan adalah mengobati, dan 60$70 \%$ dengan tujuan pengobatannya adalah pencegahan. Kegagalan untuk mengikuti program pengobatan jangka panjang, yang bukan dalam kondisi akut, dimana derajat ketidakpatuhannya rata-rata $50 \%$ dan derajat tersebut bertambah buruk sesuai waktu.

Separuh dari responden di Puskesmas Arut Utara Pangkut berumur lebh dari 40 tahun sebanyak 25 responden (50\%). Dengan bertambahnya umur seseorang akan mengalami perubahan aspek fisik dan psikologis (mental). Pada aspek psikologis atau mental, taraf berpikir seseorang semakin matang dan dewasa.

Tingkat kepatuhan setelah diberi pengetahuan di Puskesmas Arut Utara Pangkut adalah patuh sebanyak 44 responden (88\%). Adanya peningkatan jumlah responden yang patuh 
merupakan bukti nyata bahwa dengan diberikannya pengetahuan dapat merubah perilaku seseorang. Cara meningkatkan kepatuhan diantaranya melalui perilaku sehat dan pengontrolan perilaku dengan faktor kognitif, dukungan sosial dalam bentuk dukungan emosional dari anggota keluarga yang lain, teman, waktu dan uang merupakan faktor yang penting dalam kepatuhan dalam programprogram medis, dan dukungan dari profesional kesehatan Adanya perubahan angka dari sebelum diberi pengetahuan sebesar 38 responden (76\%) yang patuh menjadi 44 responden $(88 \%)$ yang patuh terlihat adanya peningkatan jumlah yang patuh sehingga merupakan hasil yang signifikan dari penambahan pengetahuan yang sudah dilakukan. Pengetahuan merupakan domain yang sangat penting bagi terbentuknya tindakan seseorang. Perilaku yang didasari oleh pengetahuan akan lebih langgeng daripada perilaku yang tidak didasari oleh pengetahuan.

Pengaruh

pengetahuan

penderita TB paru terhadap tingkat kepatuhan berobat di Puskesmas Arut Utara Pangkut . Diperoleh hasil Asymp. Sig (2 tailed) sebesar 0,014. Karena nilai Sig 0,014 $<0,05$ maka dapat disimpulkan bahwa ada pengaruh pengetahuan penderita TB paru terhadap tingkat kepatuhan berobat di Puskesmas Arut Utara Pangkut. Kepatuhan sebagai suatu proses yang dinamis, dipengaruhi oleh berbagai faktor yang tidak berdiri sendiri, memerlukan suatu kombinasi strategi promosi, memerlukan sebuah tim yang terdiri dari multidisiplin profesi yang terintegrasi dan dapat bekerjasama dengan baik dalam memberikan perawatan komprehensif berkesinambungan. Untuk itu diperlukan pendekatan yang baik dengan pasien agar dapat mengetahui kepatuhan mereka dalam melaksanakan pengobatan.

Dengan mengikuti kegiatan penambahan pengetahuan maka merupakan upaya yang dilakukan oleh keluarga sedini mungkin dalam rangka meningkatkan pengetahuan melalui pendidikan. Pendidikan adalah upaya untuk memberikan pengetahuan sehingga terjadi perubahan perilaku positif meningkat, sehingga diharapkan tingkat pendidikan yang tinggi akan meningkat pula wawasan pengetahuannya dan semakin mudah menerima pengembangan pengetahuan. Pendidikan akan menghasilkan banyak perubahan seperti pengetahuan, sikap dan perbuatan.

Pengetahuan pada dasarnya terdiri dari sejumlah fakta dan teori yang memungkinkan seseorang dapat memecahkan masalah yang dihadapinya. Pengetahuan sangat dibutuhkan agar masyarakat dapat mengetahui mengapa mereka harus melakukan suatu tindakan sehingga perilaku masyarakat dapat lebih mudah untuk diubah kearah yang lebih baik. Pengukuran pengetahuan dapat dilakukan dengan wawancara yang menanyakan sesuatu yang ingin diukur tentang pengetahuan dari subjek penelitian. 


\section{KESIMPULAN DAN SARAN}

\section{A. Kesimpulan}

Tingkat kepatuhan sebelum dan setelah diberi pengetahuan di Puskesmas Arut Utara Pangkut adalah patuh. Ada pengaruh pengetahuan penderita TB paru terhadap tingkat kepatuhan berobat di Puskesmas Arut Utara Pangkut

\section{B. Saran}

Puskesmas Arut Utara Pangkut
tetap harus melaksanakan
pendidikan kesehatan secara
kontinue tidak hanya di area
khususnya upaya preventif promotif
kuratif dan rehabilitasi penyakit TB
paru. Tenaga kesehatan juga harus
meningkatkan pelaksanaan program
pendidikan kesehatan secara
kontinue ke segala area pendidikan
di semua tingkat pendidikan.

\section{DAFTAR PUSTAKA}

World Health Organization, 2006. The Stop Tuberculose Strategy. WHO.

Laban, Yoannes. 2008. TBC Penyakit Dan Cara Pencegahannya. Yogyakarta: Kanisius.

Aditama TY, Subuh M. 2011, Strategi Nasional Pengendalian TB, Kementerian Kesehatan Republik Indonesia Direktorat Jenderal Pengendalian Penyakit Dan Penyehatan Lingkungan.

Kemkes RI. Penanggulangan TB Kini Lebih Baik. Ditjen PP\&PL Departemen Kesehatan R.I. http://www.penyakitmenular.info /def_menu.asp?menuID=1\&men uType $=$ $1 \&$ SubID=10\&DetId=868.
RPJMD Kabupaten Indramayu 20112015.

Notoatmodjo, S. 2007. Promosi Kesehatan dan Ilmu Perilaku. Jakarta : Rineka Cipta.

Jawetz, Melnick, Adelberg. 2008. Mikrobiologi Kedokteran. (H. Hartanto, C. Rachman, A. Dimanti, A. Diani). Jakarta : EGC.

Djoerban, Zubairi dan Djauzi, Samsuridjal, 2006. HIV/AIDS di Indonesia. Dalam: Sudoyo, Aru. W, dkk., ed. Buku Ajar Ilmu Penyakit Dalam Ed.IV jilid II. Jakarta: Pusat Penerbitan Departemen Ilmu Penyakit Dalam FKUI.

Depkes RI., 2011. TBC Masalah Kesehatan Dunia. Jakarta: BPPSDMK.

Notoatmodjo, S., 2007. Kesehatan Masyarakat Ilmu dan Seni. Jakarta: Rineka Cipta.

Nursalam. 2008. Konsep Dan Penerapan Metodologi Penelitian Ilmu keperawatan. Edisi 2. Jakarta : Salemba Medika.

Notoatmodjo,s. 2007. Metodologi penelitian kesehatan. Jakarta : PT Rineka Cipta.

Efendi, Ferry \& Makhfud. (2009). Keperawatan Kesehatan Komunitas Teori dan Praktik dalam Keperawatan. Jakarta : Salemba Medika.

Notoatmodjo,s. 2010. Ilmu Perilaku Kesehatan. Jakarta : PT Rineka Cipta.

Mubarak, Wahit Iqbal, 2006. Buku Ajar Keperawatan Komunitas 2. Jakarta : CV Sagung Seto.

Luluk Faizati Sholikhah, Dewi Listyorini 2012, Hubungan antara tingkat pengetahuan dan mutu pelayanan kesehatan terhadap kepatuhan minum obat penderita tuberculosis paru di puskesmas 
gatak, Skripsi mahasiswa

Fakultas ilmu Kesehatan

Universitas Muhammadiyah

Surakarta.

Made Suadnyani Pasek, I Made

Satyawan, 2013, Hubungan

Persepsi Dan Tingkat

Pengetahuan Penderita $\mathrm{Tb}$

Dengan Kepatuhan Pengobatan

Di Kecamatan Buleleng, Jurnal pendidikan Indonesia.

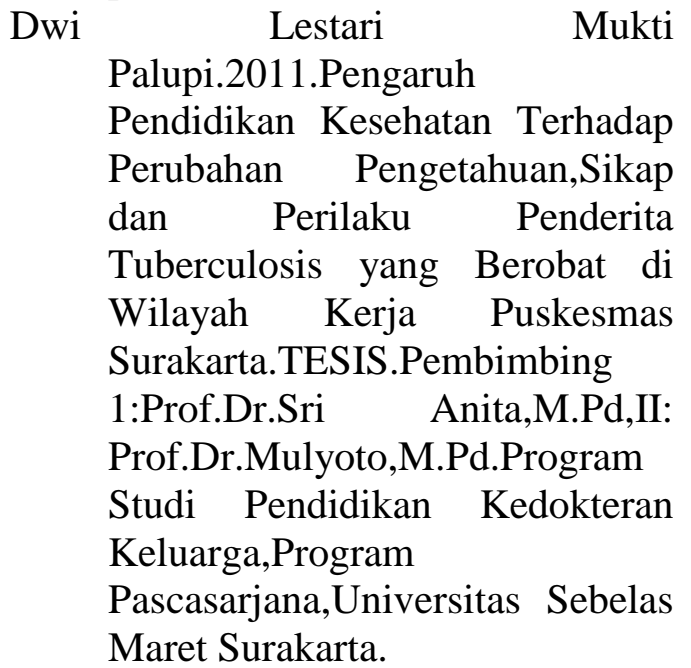

